\title{
ESTUDO DA RECICLAGEM DE CINZA VOLANTE E BIOMASSA PARA OBTENÇÃO DE AGREGADO SINTÉTICO POR MEIO DE SINTERIZAÇÃO
}

\author{
T. F. V de PINHO ${ }^{1}$, L. F. S. PEREIRA ${ }^{1}$, D. S. QUARESMA ${ }^{1}$, A. S. S. NEVES ${ }^{1}$ e J. A. S. \\ SOUZA $^{1}$. \\ ${ }^{1}$ Universidade Federal do Pará, Faculdade de Engenharia Química \\ E-mail para contato: thaianapinho@gmail.com
}

\begin{abstract}
RESUMO - A crescente preocupação com o meio ambiente, em todas as esferas do cotidiano, tem favorecido o aprimoramento de técnicas usuais. Um exemplo disso é o uso de agregados sintéticos na construção civil. O presente estudo analisa a produção de agregado sintético através da reciclagem de cinza volante e biomassa (carvão vegetal) por meio de sinterização. Confeccionaram-se pelotas com uma mistura de argila, cinza volante (resíduo) e carvão vegetal. O leito foi preenchido com $20 \%$ de pelotas e $80 \%$ de carvão. A caracterização do produto foi feita utilizando Difração de raios-X e Microscopia Eletrônica de Varredura, constatandose a presença de mulita. Medindo-se as propriedades cerâmicas do agregado produzido, obteve-se a massa específica aparente de $1,06 \mathrm{~g} / \mathrm{cm}^{3}$, classificando o material como agregado leve, segundo a ABNT 12655:2015; quanto à porosidade do agregado atingiu-se 7,26\% e a absorção de água um percentual de $6,81 \%$. Dessa forma, o processo em questão consegue reduzir os danos ambientais à medida que se substitui agregados naturais pelo material obtido.
\end{abstract}

\section{INTRODUÇÃO}

O uso de materiais alternativos na indústria da construção civil, principalmente os provenientes de resíduos industriais, tem sido cada vez mais frequente. Existem pelo menos duas razões básicas que induzem a essa realidade: a primeira deve-se ao grande volume de materiais que a construção civil demanda, e a segunda é devido à vinculação do tema, à valorização e ao uso de resíduos industriais no setor da construção civil e na área de proteção ambiental (MARGON, 2002). É neste cenário que a produção de agregado sintético a partir de resíduos industriais torna-se viável.

Agregado sintético é aquele proveniente da transformação de solo, folhelho argiloso, resíduo silico-aluminoso ou argila, previamente processado, em um material inerte e com resistência mecânica satisfatória para uma determinada finalidade. Essas características são normalmente obtidas através da queima deste material em temperaturas elevadas, com temperaturas superiores a $1100^{\circ} \mathrm{C}$. A qualidade do produto acabado depende fundamentalmente da matéria-prima utilizada, da temperatura de queima e do processo de conformação da massa cerâmica (CABRAL, 2008). 
A queima do carvão mineral em caldeiras de uma central termoelétrica gera vapor e produz resíduos durante o processo da combustão do carvão, conhecidas como cinzas. A reutilização de cinzas na formulação de argamassas e concretos é uma alternativa interessante, visto que este material possui atividade pozolânica (SIQUEIRA, 2012).

No processo de sinterização é feito uma mistura da matéria prima com uma quantidade definida de combustível, podendo ser carvão finamente moído ou coque. Posteriormente esse material é exposto a temperaturas elevadas, que tem como consequência a expansão devido à formação de gases (GOMES, 1998).

O uso energético da biomassa (fonte renovável) vem sendo valorizado como forma alternativa ao uso de combustíveis fósseis. A biomassa utilizada neste trabalho é o carvão vegetal, proveniente da queima parcial da madeira ou de outra biomassa vegetal.

Tendo em vista isso, este trabalho tem por objetivo o estudo da reciclagem de cinza de carvão mineral (cinza volante) e biomassa para produção de agregado sintético por meio de sinterização, aplicando-a em uma mistura de argila e carvão vegetal - biomassa que será o combustível sólido da sinterização.

\section{MATERIAIS E MÉTODOS}

A cinza volante de carvão mineral foi cedida pela HYDROALUNORTE (Alumina do Norte do Brasil S/A) e corresponde ao rejeito industrial a ser aproveitado no processo, atuando como fundente e ocasionando a diminuição da temperatura no processo de sinterização. A cinza, como apresenta partículas finamente divididas, não necessitou de tratamento prévio e foi utilizada de forma direta nos experimentos.

A argila retirada das margens do rio Guamá foi previamente seca a $105^{\circ} \mathrm{C}$ em estufa com recirculação de ar durante 24 horas e posteriormente desagregada em moinho de bolas por 30 minutos.

O carvão vegetal, obtido comercialmente, foi submetido ao mesmo pré-tratamento realizado com a argila e foi, posteriormente, empregada como combustível sólido no processo de sinterização.

O processo de sinterização foi realizado com uma mistura de $20 \%$ do volume do reator de pelotas (constituída a partir das matérias-primas) e $80 \%$ de carvão vegetal em todos os experimentos. A velocidade de sucção de ar utilizada no experimento de $0,97 \mathrm{~m} \cdot \mathrm{s}^{-1}$.

O preparo das pelotas foi realizado a partir de uma mistura de $40 \%$ de cinza, $30 \%$ de argila e 30\% de carvão em peso, a qual foi adicionada ao moinho de bolas para promover a homogeneização durante 60 minutos, posteriormente a mesma foi colocada em um tambor rotativo onde as pelotas eram formadas com adição de $40 \%$ de água em peso, apresentando tamanhos variados. 


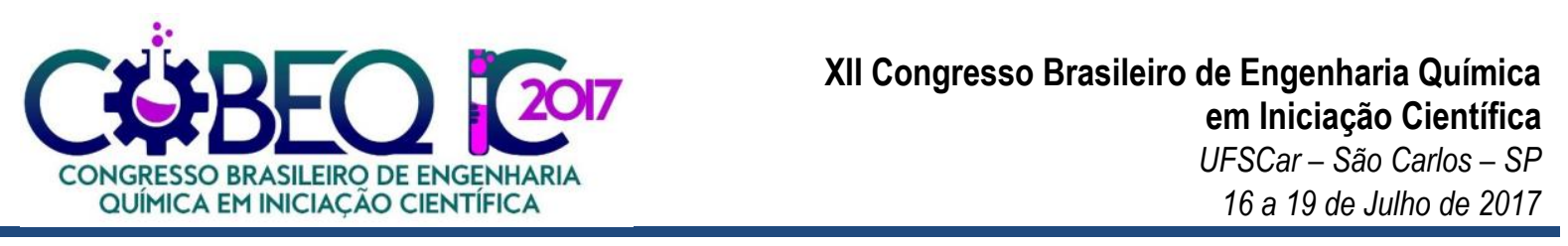

Após essa etapa, as pelotas foram colocadas em estufa à temperatura de $105^{\circ} \mathrm{C}$ durante 24 horas para secagem, seguida de classificação para uma granulometria inferior a $6,35 \mathrm{~mm}$ e maior ou igual a $4 \mathrm{~mm}$. Em seguida fez-se uma caracterização quanto a sua distribuição granulométrica e densidade aparente.

Para a preparação do carvão que preencheu $80 \%$ do volume do reator, realizou-se um processo de secagem durante 24 horas a $105^{\circ} \mathrm{C}$, britagem e moagem em moinho de discos. Ato contínuo ao processo, o material foi classificado para uma granulometria inferior a $3,36 \mathrm{~mm}$ e maior ou igual a 1,70mm e após essa etapa fez-se a análise granulométrica e a determinação da densidade aparente do material. Após essa etapa os materiais foram homogeneizados manualmente. Preparada a mistura, a mesma foi submetida a secagem por 24 horas a $105^{\circ} \mathrm{C} \mathrm{em}$ estufa com recirculação de ar e em seguida sinterizada em um reator vertical.

Para o início do experimento, um maçarico acoplado a um botijão de gás GLP, executa a queima do gás e proporciona uma chama regulável, o qual é utilizado na parte superior do reator para dar ignição à combustão, definida para uma temperatura de $700^{\circ} \mathrm{C}$. Um ventilador é adaptado através de um tubo de aço carbono conectado a parte inferior do reator para succionar o ar, que contém o comburente da reação, promovendo assim o avanço da frente de combustão dentro do reator. A análise do avanço da frente de combustão e das temperaturas no interior do leito é feito através da medição de temperaturas utilizando-se termopares dispostos verticalmente no reator. A aquisição dos dados de temperatura foi registrada no Paperless Recorder, tipo PHL a cada 5 segundos. Após processo de sinterização obteve-se o agregado sintético apresentando tamanhos variados, conforme pode ser observado na Figura 1.

Figura 1 - Agregados sintéticos produzidos.

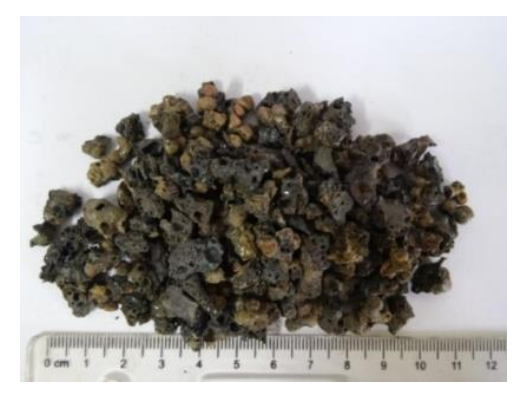

Realizaram-se ensaios para a determinação das propriedades cerâmicas do material como: Porosidade Aparente (PA), Absorção de Água (AA) e Massa Especifica Aparente (MEA), através do método citado por SANTOS (1989). Além dessas análises no agregado produzido fez-se difração de raios-X para identificação das fases mineralógicas e Microscopia Eletrônica de Varredura para análise dos elementos microestruturais.

\section{RESULTADOS E DISCUSSÕES}

A distribuição granulométrica das pelotas e do carvão vegetal classificados para a realização do experimento está apresentada na Figura 2, onde apresentaram diâmetro médio no valor de $6,85 \mathrm{~mm}$ para as pelotas e $2,17 \mathrm{~mm}$ para o carvão vegetal. 


\section{Congresso Brasileiro de Engenharia Química \\ em Iniciação Científica \\ UFSCar - São Carlos - SP

Figura 2 - Distribuição granulométrica das pelotas (a) e do carvão vegetal (b).

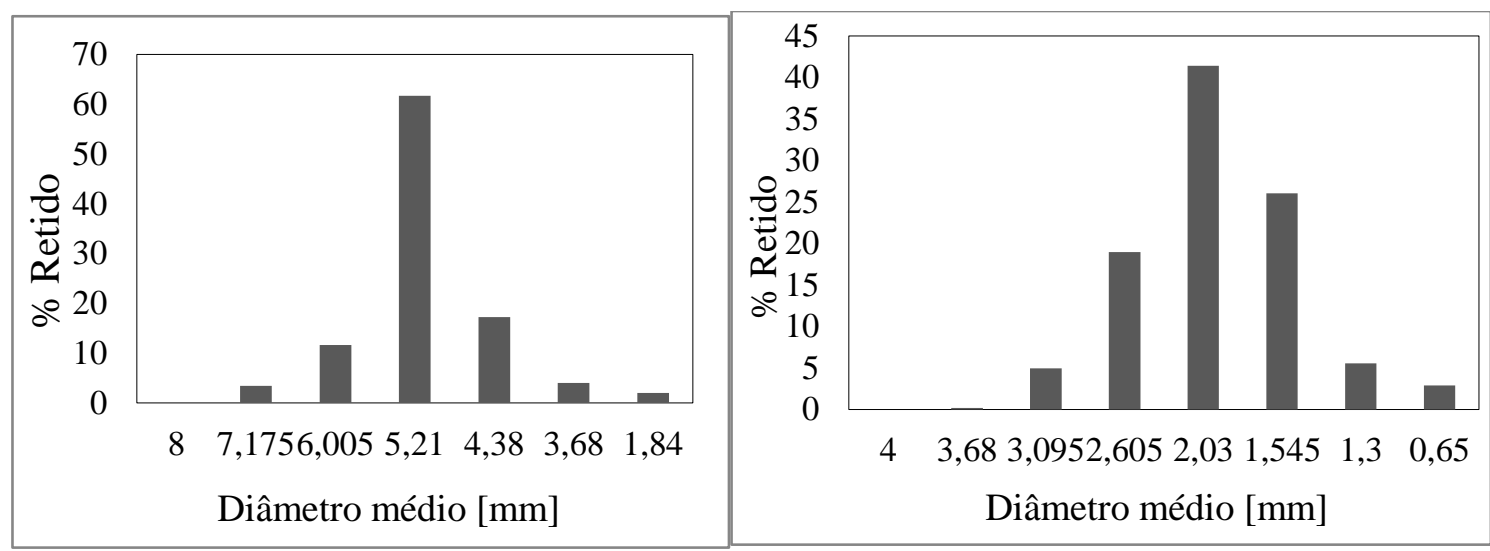

(a)

(b)

A Figura 3 consta essa evolução para o experimento. As evoluções da temperatura para cada termopar representada na Figura 3 possuem aspectos semelhantes, em que a temperatura em cada termopar atingiu um valor máximo seguido de uma redução gradual, caracterizando o avanço da frente de combustão. $\mathrm{O}$ valor máximo de temperatura registrado foi de $1.324,1^{\circ} \mathrm{C}$

Figura 3 - Evolução da temperatura do experimento.

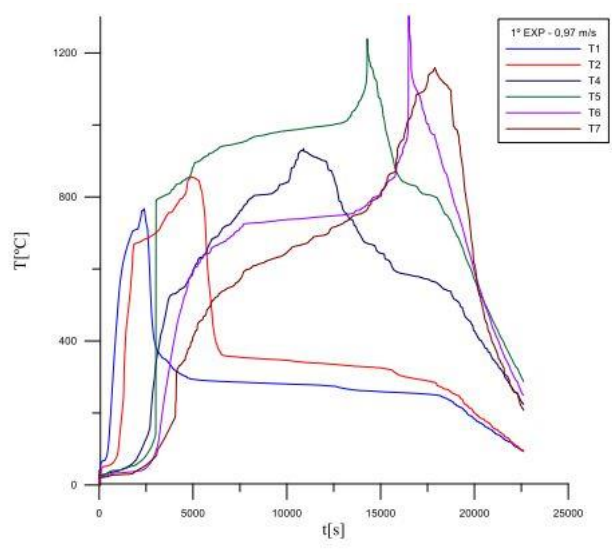

Os resultados obtidos com a medida das propriedades cerâmicas do agregado sintético para os experimentos constituem a Tabela 1.

Tabela 1 - Medida das propriedades cerâmicas do material produzido

\begin{tabular}{|c|c|}
\hline Propriedades & Experimento \\
\hline \hline PA (\%) & 7,26 \\
\hline AA (\%) & 6,81 \\
\hline MEA [g.cm $\left.{ }^{-3}\right]$ & 1,06 \\
\hline
\end{tabular}


Agregado classificado como leve, apresenta um valor de MEA inferior a 2,0 g/ $\mathrm{cm}^{3}$, segundo a ABNT NBR 9935:2011, o qual pode ser evidenciado nos resultados expostos na Tabela 1.

Os resultados obtidos evidenciam que com o aumento da porosidade aparente tem-se um aumento gradativo da absorção de água e consequente diminuição da massa especifica aparente, fato que pode ser explicado quando se refere a produção de agregado leve por meio de sinterização, mostrando que estes apresentam elevada capacidade de absorção de água, poros abertos, além de não possuir recobrimento. A Microscopia Eletrônica de Varredura (MEV) para uma amostra do agregado produzido no está representada na Figura 4.

Figura 4 - Micrografia do agregado produzido no experimento.

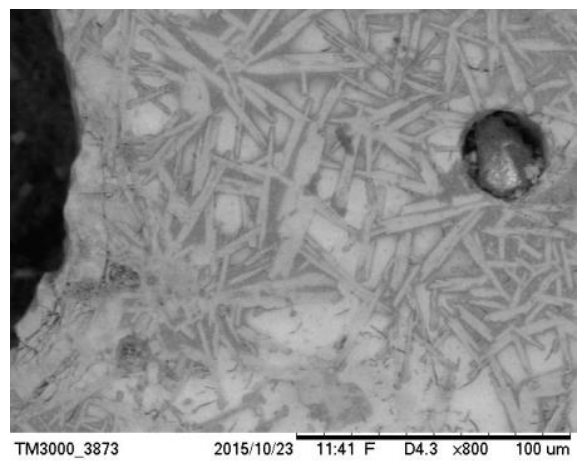

(a)

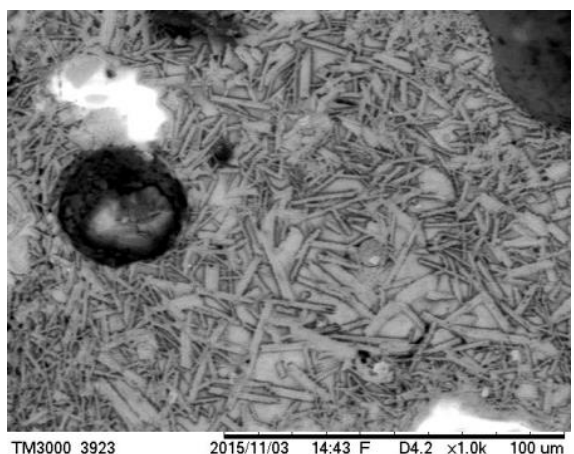

(b)

Pode ser observado na Figura 4 que ocorreu a formação de mulita primária e secundária de morfologia acicular. Esta formação é vinculada as reações de estado sólido que são funções da temperatura, acima de $1000^{\circ} \mathrm{C}$, e da composição da mistura, a qual é formada majoritariamente por sílico-aluminatos.

A Figura 5 apresenta os difratogramas realizados nos agregados sintéticos no experimento. Os resultados mostram a presença de quartzo $\left(\mathrm{SiO}_{2}\right)$, mulita $\left(3 \mathrm{Al}_{2} \mathrm{O}_{3} \cdot 2 \mathrm{SiO}_{2}\right)$, anortita $\left(\mathrm{CaAl}_{2} \mathrm{Si}_{2} \mathrm{O}_{8}\right)$ e esseneite $\left(\mathrm{CaFe}^{3+} \mathrm{AlSiO}_{6}\right)$. A formação de quartzo é justificada pela presença de sílica em temperaturas acima de $500^{\circ} \mathrm{C}$ segundo o diagrama de fases. A fase mulita está relacionada a presença de sílico-aluminatos em temperaturas acima de $1000^{\circ} \mathrm{C}$. A constatação das fases anortita e esseneite está vinculada também a presença de sílico aluminatos, além de cálcio e ferro disponível em temperaturas favoráveis, superior a $1000^{\circ} \mathrm{C}$.

Figura 5- Difratogramas referente aos agregados produzidos no Experimento.

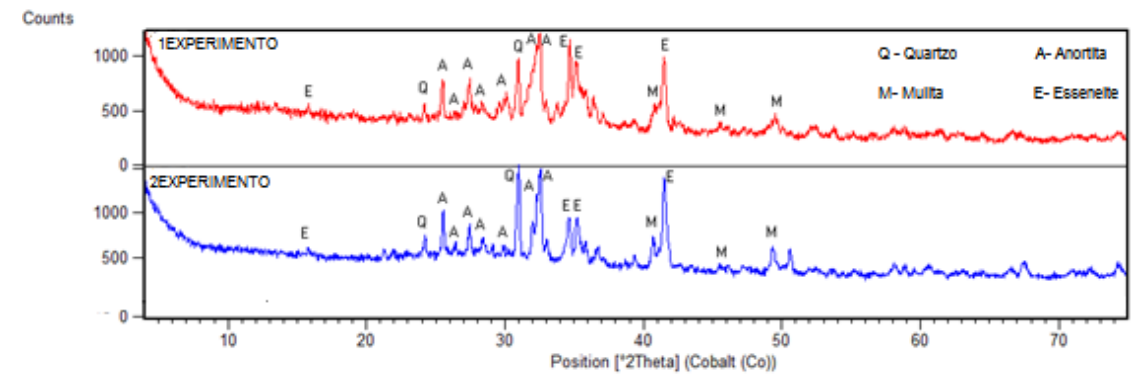




\section{CONCLUSÃO}

Materiais ricos em sílica e alumina como cinza volante e argila, sinterizados a partir de $1000^{\circ} \mathrm{C}$ reagem formando mulita, composto estável, responsável pela característica de resistência ao material. Quando comparados os dois experimentos, constata-se que a variação de velocidade entre estes não interfiriu qualitativamente na formação de mulita comprovada nas análises de microscopia eletrônica de varredura e difração de raios-X.

Em conjunto com os dados obtidos para massa específica aparente, os quais classificaram os agregados produzidos como leve, os valores elevados de porosidade e absorção aparente, formam resultados característicos do processo de sinterização de agregado leve.

A granulometria definida tanto das pelotas quanto do carvão vegetal permitiu que o leito do reator fosse suficientemente poroso para permitir o fluxo do ar e a propagação da frente de combustão, e assim garantir a sinterização das pelotas, durante as reações de combustão do carvão vegetal.

Desta forma a contribuição desse trabalho é com relação à capacidade que o material produzido tem em substituir agregados naturais, com controle de MEA e resistência mecânica, melhorando a qualidade do concreto e contribuindo para a preservação ambiental.

\section{REFERÊNCIAS}

CABRAL, E. M., SÁ, R. J., VIEIRA, R. K., VASCONCELOS, R. P. Utilização de massas cerâmicas na produção de agregado sintético de argila calcinada para uso em concreto. Cerâmica, v. 54, pp 404-410. 2008.

GOMES NETO, D. P. Dosagem de microconcretos leves de alto desempenho para produção de pré-fabricados de pequena espessura: estudo de caso. 1998. Dissertação (Mestrado) Escola de Engenharia de São Carlos, Universidade de São Paulo, São Carlos, 1998.

MARGON, P. V. Influência do uso das cinzas de carvão mineral de termelétricas em argamassas de revestimento: dosagem por curvas granulométricas. 2002, 4p. Dissertação (Mestrado) - Programa de Pós-Graduação em Engenharia Civil, Universidade Federal de Santa Catarina, Florianópolis, 2002.

MARTINS, M.F.; Structure d'un front de combustion propagé en co-courant dansun lit fixe de schistebitumineuxbroyé, Doctorat de L'Université de Toulouse - L'Institut National Polytechnique de Toulouse - França; 2008.

SIQUEIRA, J. S. SOUZA, C. A. G., SOUZA, J. A. S. Reaproveitamento de cinzas de carvão mineral na formulação de argamassas. Cerâmica, v.58, pp 275-279. 2012. 